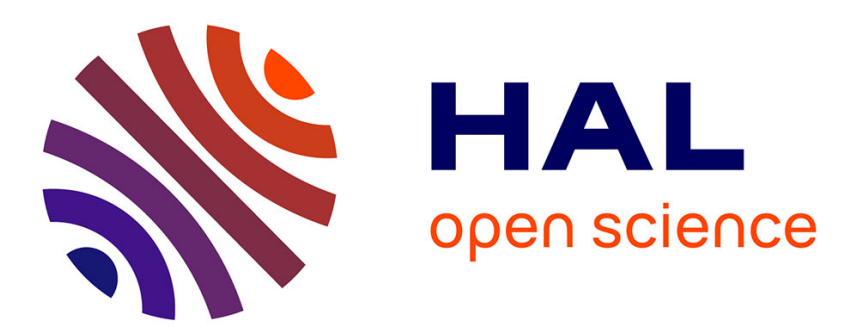

\title{
A simplified heat transfer model of a closed refrigerated display cabinet
}

Nattawut Chaomuang, Onrawee Laguerre, D. Flick

\section{To cite this version:}

Nattawut Chaomuang, Onrawee Laguerre, D. Flick. A simplified heat transfer model of a closed refrigerated display cabinet. International Congress of Refrigeration, Jul 2019, Montréal, Canada. 10.18462/iir.icr.2019.0049 . hal-03261470

\section{HAL Id: hal-03261470 \\ https://hal.inrae.fr/hal-03261470}

Submitted on 15 Jun 2021

HAL is a multi-disciplinary open access archive for the deposit and dissemination of scientific research documents, whether they are published or not. The documents may come from teaching and research institutions in France or abroad, or from public or private research centers.
L'archive ouverte pluridisciplinaire HAL, est destinée au dépôt et à la diffusion de documents scientifiques de niveau recherche, publiés ou non, émanant des établissements d'enseignement et de recherche français ou étrangers, des laboratoires publics ou privés. 
Manuscript ID: 49

DOI: $10.18462 /$ iir.icr.2019.0049

\title{
A simplified heat transfer model of a closed refrigerated display cabinet

\author{
Nattawut CHAOMUANG ${ }^{(a)(b)(c)}$, Onrawee LAGUERRE ${ }^{(a)}$, \\ Denis FLICK ${ }^{(b)}$
}

(a) UR GPAN, Refrigeration Processing Engineering Research Unit, Irstea

1 rue Pierre-Gilles de Gennes, Antony, 92160, France, nattawut.chaomuang@irstea.fr

(b) AgroParisTech, Inra, Université Paris-Saclay, UMR Ingénierie Procédés Aliments

Massy, 91300, France

(c) Department of Food Engineering, King Mongkut's Institute of Technology Ladkrabang

Bangkok, 10520, Thailand

\begin{abstract}
A simplified heat transfer model for a closed refrigerated display cabinet was developed based on a zonal approach. The developed model allows the prediction of time-averaged air and load temperatures at various positions in the display cabinet. These predicted values were compared with measured air and load temperatures. Good agreement was found between them with the maximum difference of $0.5^{\circ} \mathrm{C}$ for every studied position and the overall mean absolute error of $0.2^{\circ} \mathrm{C}$. Air and load temperatures vary with positions. High temperature was observed at the front (highest value at the front top) and low at the back (lowest value at the back bottom). Based on the simulation, the cabinet thermal performance can be enhanced by minimizing the size of door gaps.

Keywords: Closed refrigerated display cabinet, Simplified model, Heat transfer, Temperature
\end{abstract}

\section{INTRODUCTION}

It is well known that air infiltration across an air curtain is one of the major drawbacks of open refrigerated display cabinets. It accounts for about $66-77 \%$ of total refrigeration loads (Gaspar et al., 2011) and also causes temperature heterogeneity in the cabinets (Laguerre et al., $2012 b$ ). High temperature is mostly at the front areas and low temperature at the rear (Evans et al., 2007). As temperature is one of the most important factors affecting food quality and safety, minimizing the air infiltration would prolong product shelf life.

Installation of doors on the open cabinets is one of the simple and effective solutions for the air infiltration reduction. Many achievements were demonstrated by various studies: energy saving potential (Faramarzi et al., 2002; Fricke and Becker, 2010), better temperature homogeneity (Chaomuang et al., 2019; Lindberg et al., 2010) and slower quality decay (Atilio de Frias et al., 2015). As a result, the use of display cabinets with doors is increasingly used in retail stores worldwide. Closed display cabinets will account for about $75 \%$ of all operating display cabinets by 2020 in France (RPF, 2016).

Because door installation can modify airflow pattern and temperature distribution inside the cabinet (Faramarzi et al., 2002), an understanding of mechanism of heat transfer and airflow in the equipment becomes necessary to ensure food quality and safety. Although numerical simulation with CFD (Computational Fluid Dynamics) models is widely used to investigate the thermal phenomena in many refrigerating equipment (Smale et al., 2006), this approach entails some limitations because of the requirement of calculation time and computational resources. A simplified heat transfer model based on a zonal approach becomes a complementary option as demonstrated by Laguerre et al. (2012a). They applied such a model to assess the influence of operating conditions and equipment design on temperature of products stored in an open display cabinet under steady state. 
This work on a closed display cabinet is a continuity of the previous studies of which the objective is to present a simplified heat transfer model based on the zonal approach. This developed model enables the understanding of the heat transfer phenomena in the equipment as well as the prediction of internal temperature distribution.

This developed heat transfer model will be further integrated with the other models already developed by our teams for several refrigerating equipment. By this mean, it allows the prediction of time-temperature history of food products from a production plant to a household refrigerator. Furthermore, these models linked with predictive microbiological and/or quality models can be used as an evaluation tool for consumer risk (Duret et al., 2015).

\section{MATERIALS AND METHOD}

\subsection{Experimental setup}

Temperature measurement was carried out in a closed refrigerated display cabinet loaded with test packages made of methylcellulose. This cabinet was installed in a test room in which the ambient temperature was controlled at $19.5^{\circ} \mathrm{C}$. The lights in the test room and in the cabinet were switched on to represent the real-use condition in supermarket and the cabinet doors were always closed during the experiment. As shown in Fig.1, calibrated thermocouples (T-type, accuracy $\pm 0.2^{\circ} \mathrm{C}$ ) were placed at various positions in the cabinet for the measurement of air and load (core and surface) temperatures. Perforation pattern of the back panel (PBP) of the studied cabinet is also depicted in this figure. According to the total plate area over each shelf, there are $2.3 \%$ of holes at the top shelf, $8.3 \%$ at the bottom shelf and $3.8 \%$ at all intermediate shelves. The temperatures were recorded every $10 \mathrm{~s}$ using a data logger for 24 hours. The time-averaged values were then calculated over $5 \mathrm{~h}$ of the quasi-steady state during which the defrosting period was excluded from the calculation. These results were then used for the model validation.

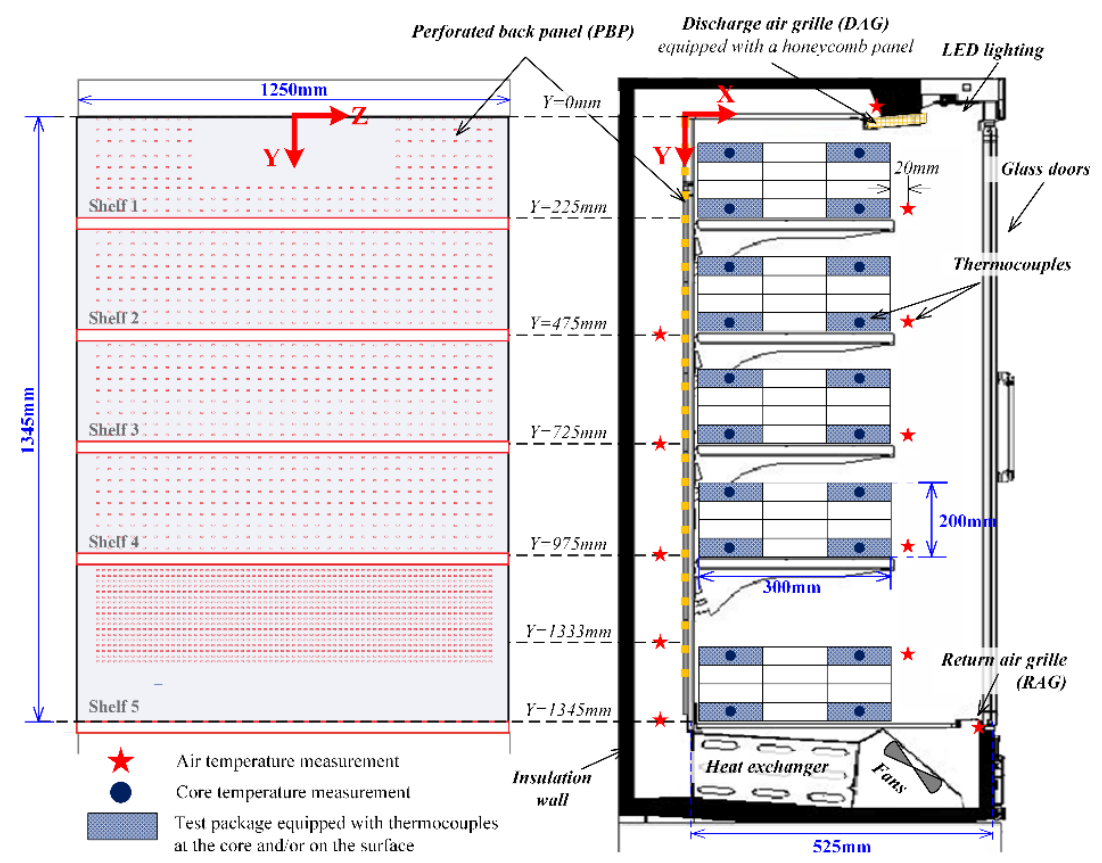

Figure 1: Experimental setup for the temperature measurement

\subsection{Model development}

\subsubsection{Model description}

A steady state model is developed in the present study to predict the time-averaged air and load temperatures in the closed refrigerated display cabinet. The air temperature just after the 
heat exchanger at which the thermostat sensor is located $\left(T_{t h}\right)$ and the external air temperature $\left(T_{\text {ext }}\right)$ are the input parameters which are assumed constant. To generalize the model, dimensionless temperature $\left(\theta_{i}\right)$ based on these temperatures is defined as follows:

$$
\theta_{i}=\frac{\bar{T}_{i}-\bar{T}_{t h}}{T_{\text {ext }}-\bar{T}_{t h}}
$$

\subsubsection{Zone definition}

Based on the zonal approach, heat exchange zones at different positions in the cabinet were established (Fig.2). Two main domains were considered, the first one represents the heat transfer in the rear duct where cold air exchanges heat with the ambient air through the rear wall while the second one represents the heat transfer in the shelf space.

\subsubsection{Heat balance equations}

For every zone in both domains, algebraic heat balance equations were derived to describe the heat transfers in the display cabinet.

Starting from Domain I and Position 1 (denoted by EZ [1,1], Fig. 2), the supply air (mass flow rate $\dot{m}_{t}$ and temperature $\left.\theta_{t h}\right)$ exchanges heat with the external air $\left(\theta_{\text {ext }}\right)$ through the rear wall by conduction and by convection (overall heat transfer coefficient $U_{\text {ovw }}$ ). The air temperature then increases to $\theta_{\text {ard } 1}$. By integration along the rear duct located at this position, the heat balance equation becomes:

$$
\theta_{\text {ard } 1}=\alpha_{r d 1} \theta_{t h}+\left(1-\alpha_{r d 1}\right) \theta_{\text {ext }} \text { where } \alpha_{r d 1}=\exp \left(-\frac{U_{o v w} s_{w 1}}{\dot{m}_{t} C_{p a}}\right)
$$

A part of air flows into the shelve space through the perforated back panel (PBP) while the remaining part (mass flow rate $\dot{m}_{\text {ard }}$ ) continues flowing towards the discharge air grille (DAG), along which the air temperature increases successively to $\theta_{\operatorname{ard7} 7}$. The heat balance of $\mathrm{EZ}$ $[1,2 \ldots 7]$ was therefore carried out in the same manner as that of EZ $[1,1]$.

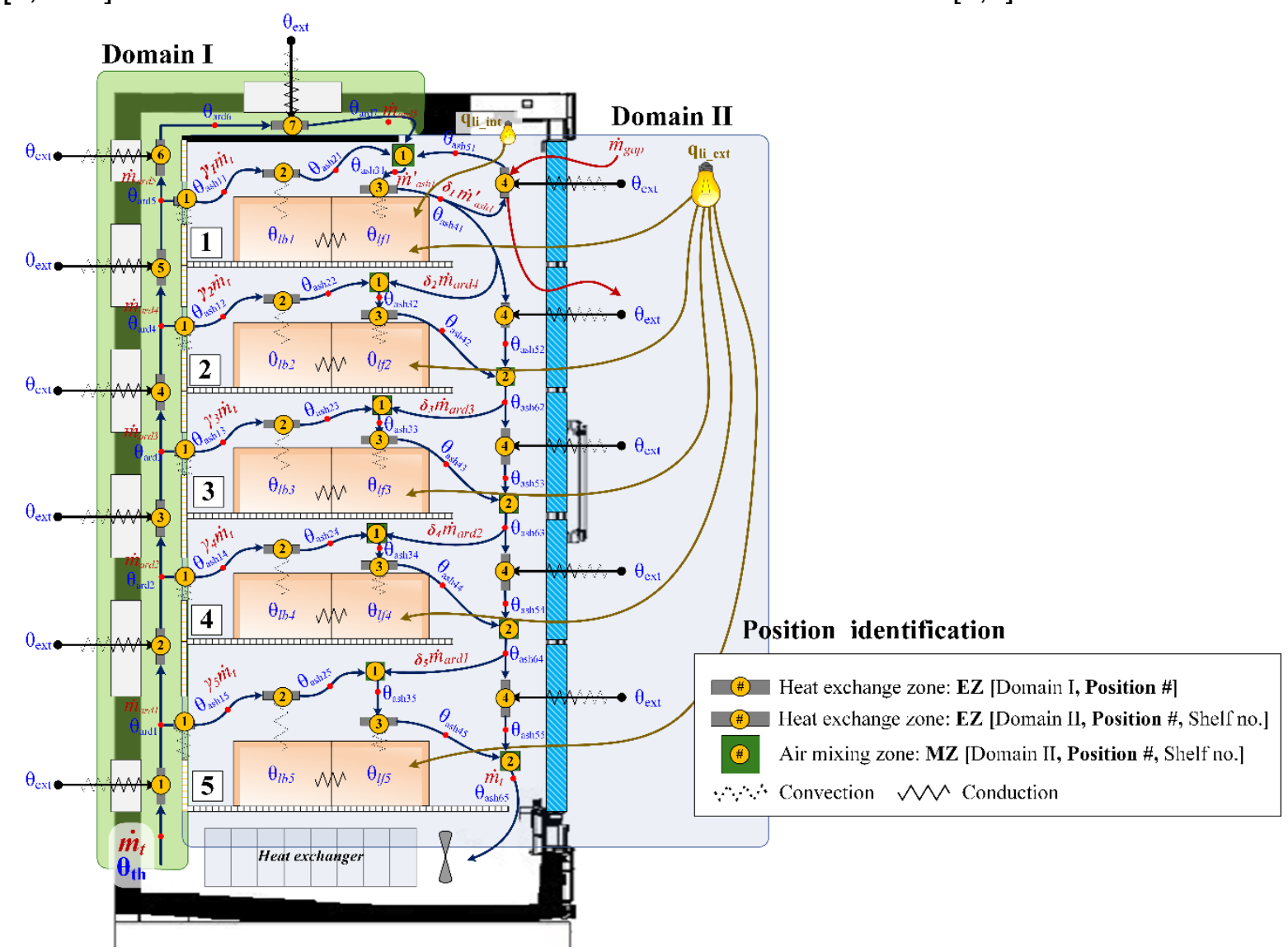

Figure 2: Schematic view of the simplified heat transfer model of a closed refrigerated display cabinet. 
Domain II is composed of five shelves. Each shelf has four heat exchange zones (EZ $[2,1 \ldots 4,1 \ldots 5])$ and one or two air mixing zones $(M Z[2,1 \ldots 2,1 \ldots 5])$. At Position 1 Shelf 1 , i.e. EZ $[2,1,1]$ (see Fig. 2), a part of the air (mass flow rate $\dot{m}_{a s h 1}=\gamma_{1} \dot{m}_{t}$ and temperature $\theta_{\text {ard } 5}$ ) flows horizontally through PBP at the mid height of Shelf 1 . At the steady state, the air temperatures before and after flowing through PBP are the same:

$$
\theta_{\text {ash } 11}=\theta_{\operatorname{ard} d 5}
$$

At EZ $[2,2,1]$, the air (temperature $\theta_{a s h 11}$ ) exchanges heat by convection (heat transfer coefficient $U_{l b 1}$ ) with the back load (temperature $\theta_{l b 1}$ ). The air temperature becomes $\theta_{a s h 21}$.

$$
\theta_{a s h 21}=\alpha_{s h 11} \theta_{a s h 11}+\left(1-\alpha_{s h 11}\right) \theta_{l b 1} \text { where } \alpha_{s h 11}=\exp \left(-\frac{U_{l b 1} s_{l 1}}{\dot{m}_{a s h 1} c_{p a}}\right)
$$

In addition to this convective heat exchange with air, the back load also exchanges heat with the front one by conduction (heat transfer coefficient $U_{l l 1}$ ) because of the contact between these two loads.

$$
\theta_{a s h 21}=\theta_{a s h 11}+\beta_{s h 11}\left(\theta_{l f 1}-\theta_{l b 1}\right) \text { where } \beta_{s h 11}=\frac{U_{l l 1} s_{l l 1}}{\dot{m}_{a s h 1} c_{p a}}
$$

A similar heat balance was developed for other shelves.

The air then mixes with other two air streams at MZ [2,1,1] (Fig. 2) including air from DAG (mass flow rate $\dot{m}_{\text {ard } 5}$ and temperature $\theta_{\text {ard } 7}$ ) and a part of the recirculating air (mass flow rate $\delta_{1} \dot{m}_{a s h 1}^{\prime}$ and temperature $\theta_{a s h 51}$ ).

$$
\dot{m}_{a s h 1}^{\prime} \theta_{a s h 31}=\dot{m}_{a r d 5} \theta_{a r d 7}+\dot{m}_{a s h 1} \theta_{a s h 21}+\delta_{1} \dot{m}_{a s h 1}^{\prime} \theta_{a s h 51} \text { where } \dot{m}_{a s h 1}^{\prime}=\frac{\dot{m}_{a s h 1}+\dot{m}_{a r d 5}}{1-\delta_{1}} \text { Eq. }
$$

This mixed air then exchanges heat with the front load, EZ [2,3,1], and its temperature becomes $\theta_{\text {ash } 41}$.

$$
\theta_{a s h 41}=\alpha_{s h 21} \theta_{a s h 31}+\left(1-\alpha_{s h 21}\right) \theta_{l f 1} \text { where } \alpha_{s h 21}=\exp \left(-\frac{U_{l f 1} S_{l 1}}{\dot{m}_{a s h 1}^{\prime} c_{p a}}\right)
$$

In addition to this convective heat exchange with the air, the front load also exchanges heat with the back load by conduction (heat transfer coefficient, $U_{l l 1}$ ) and receives heat from the conversion of the room and cabinet lighting powers $\left(q_{l i}\right)$. At steady state:

$\theta_{a s h 41}=\theta_{a s h 31}+\beta_{s h 21}\left(\theta_{l b 1}-\theta_{l f 1}\right)+q^{\prime \prime}{ }_{l i 1}$ where $\beta_{s h 21}=\frac{U_{l l 1} s_{l l 1}}{\dot{m}_{a s h 1}^{\prime} c_{p a}} ; q^{\prime \prime}{ }_{l i 1}=\frac{q_{l i 1}}{\dot{m}_{a s h 1}^{\prime} c_{p a}\left(T_{e x t}-\bar{T}_{t h}\right)}$

Unlike Shelf 1, different heat balance is applied to the other shelves. The heat transfer mechanism on Shelf 2 was selected as a sample of the model development. The air flowing through PBP (mass flow rate $\dot{m}_{a s h 2}$ and temperature $\theta_{a s h 22}$ ) mixes with a part of the air curtain from the upper shelf (mass flow rate $\delta_{2} \dot{m}_{\text {ard } 4}$ and temperature $\theta_{\text {ash } 41}$ ).

$$
\dot{m}_{a s h 2}^{\prime} \theta_{a s h 32}=\dot{m}_{a s h 2} \theta_{a s h 22}+\delta_{2} \dot{m}_{a r d 4} \theta_{a s h 41} \text { where } \dot{m}_{a s h 2}^{\prime}=\dot{m}_{a s h 2}+\delta_{2} \dot{m}_{a r d 4}
$$

Then, the mixed air exchanges heat with the front load, EZ [2,3,2], and its temperature becomes $\theta_{\text {ash } 42}$.

$$
\theta_{a s h 42}=\alpha_{s h 22} \theta_{a s h 32}+\left(1-\alpha_{s h 22}\right) \theta_{l f 2} \text { where } \alpha_{s h 22}=\exp \left(-\frac{U_{l f 2} S_{l 2}}{\dot{m}_{a s h 2}^{\prime} C_{p a}}\right)
$$

The load located at the front of Shelf 2 is subjected to the convection with the mixed air, the conduction with the adjacent load at the back (heat transfer coefficient $U_{l l 2}$ ) and the heat conversion of visible radiation from the room lighting power $\left(q_{l i 2}\right)$, thus

$$
\theta_{a s h 42}=\theta_{a s h 32}+\beta_{s h 22}\left(\theta_{l b 2}-\theta_{l f 2}\right)+q^{\prime \prime}{ }_{l i 2} \text { where } \beta_{s h 22}=\frac{U_{l l 2} S_{l l 2}}{\dot{m}_{a s h 2} C_{p a}} ; q^{\prime \prime}{ }_{l i 2}=\frac{q_{l i 2}}{\dot{m}_{a s h 2}^{\prime} C_{p a}\left(T_{e x t}-\bar{T}_{t h}\right)}
$$


After exchanging heat with the front load, a part of the air at Shelf 1 (mass flow rate $\delta_{1} \dot{m}_{a s h 1}$ and temperature $\theta_{a s h 41}$ ) flows toward the doors and is submitted to heat losses through the doors (overall heat transfer coefficient $U_{o v d}$ ). This air also interacts with the air infiltration through the door gaps (mass flow rate $\dot{m}_{\text {gap }}$ ). These exchanges at EZ $[2,4,1]$ result in an air temperature increase to $\theta_{\text {ash } 51}$.

$$
\theta_{a s h 51}=\alpha_{s h 31} \theta_{a s h 41}+\left(1-\alpha_{s h 31}\right) \theta_{\text {ext }} \text { where } \alpha_{s h 31}=\exp \left(-\frac{C_{e q} s_{d 1}}{\delta_{1} \dot{m}_{a s h 1}^{\prime} c_{p a}}\right)
$$

For simplification and as a first approach, it is considered that there is no air recirulation and air infiltration through the door gaps for the other shelves. A part of the air at these shelves, e.g. Shelf 2 , is mixed with the air from the top shelf (mass flow rate $\left(1-\delta_{2}\right) \dot{m}_{\text {ard } 4}$ and temperature $\theta_{a s h 41}$ ) and exchanges heat with the external ambient air through the glass doors (overall heat transfer coefficient $U_{\text {ovd }}$ ).

$$
\theta_{\text {ash } 52}=\alpha_{s h 32} \theta_{\text {ash } 41}+\left(1-\alpha_{s h 32}\right) \theta_{\text {ext }} \text { where } \alpha_{s h 32}=\exp \left(-\frac{U_{o v d} S_{d 2}}{\left(1-\delta_{2}\right) \dot{m}_{a r d 4} C_{p a}}\right)
$$

This air then mixes with the air which exchanged heat with the load located at the front of the shelf at MZ $[2,2,2]$.

$$
\dot{m}_{a r d 3} \theta_{a s h 62}=\dot{m}_{a s h 2}^{\prime} \theta_{a s h 42}+\left(1-\delta_{2}\right) \dot{m}_{a r d 4} \theta_{a s h 52}
$$

A similar heat and mass balances at $E Z[2,4,2]$ and $M Z[2,2,2]$ were applied to Shelf 3 to 5 . Input parameters used in the developed model were obtained from several sources: physical measurement, calculation based on literature and material properties and model fitting as

\begin{tabular}{|c|c|c|c|c|c|c|}
\hline Parameter & & Value & Source & & Value & Source \\
\hline Mass flow rate $\left(\mathrm{kg} \cdot \mathrm{s}^{-1}\right)$ & $\dot{m}_{t}$ & 0.1120 & Measurement & $\dot{m}_{\text {gap }}$ & 0.0051 & Model fitting \\
\hline \multirow{5}{*}{$\begin{array}{l}\text { Air distribution } \\
\text { coefficient (-) }\end{array}$} & $\gamma_{1}$ & 0.02 & \multirow[t]{5}{*}{ Measurement } & $\delta_{1}$ & 0.90 & \multirow[t]{5}{*}{ Model fitting } \\
\hline & $\gamma_{2}$ & 0.02 & & $\delta_{2}$ & 0.70 & \\
\hline & $\gamma_{3}$ & 0.04 & & $\delta_{3}$ & 0.70 & \\
\hline & $\gamma_{4}$ & 0.05 & & $\delta_{4}$ & 0.70 & \\
\hline & $\gamma_{5}$ & 0.36 & & $\delta_{5}$ & 0.70 & \\
\hline \multirow{3}{*}{$\begin{array}{l}\text { Heat transfer } \\
\text { coefficient } \\
\left(\mathrm{W} \cdot \mathrm{m}^{-2} \cdot \mathrm{K}^{-1}\right)\end{array}$} & $U_{l b}$ & 15 & Model fitting & $U_{o v w}$ & 0.77 & Calculation \\
\hline & $U_{l f}$ & 24 & Model fitting & $U_{\text {ovd }}$ & 1.02 & Calculation \\
\hline & $U_{l l}$ & 3.4 & Calculation & $C_{e a}$ & 17.6 & Calculation \\
\hline \multirow{3}{*}{$\begin{array}{l}\text { Exchange area* } \\
\left(\mathrm{m}^{2}\right)\end{array}$} & $S_{w 1}$ & 0.216 & Measurement & $S_{c}$ & 0.500 & Measurement \\
\hline & $S_{w 2 \ldots 5}$ & 0.313 & Measurement & $S_{d 1 \ldots 4}$ & 0.313 & Measurement \\
\hline & $S_{w 6}$ & 0.156 & Measurement & $S_{d 5}$ & 0.431 & Measurement \\
\hline Lighting power (W) & $q_{l i 1}$ & 10 & Calculation & $q_{l i 2 \ldots 5}$ & 0.25 & Calculation \\
\hline
\end{tabular}
summarized in Table 1. The simulation was run on MATLAB environment.

Table 1 Values of input parameters used in the simplified heat transfer model

\section{RESULTS AND DISCUSSION}

Fig. 3a shows the predicted and measured air and load temperatures inside the closed display cabinet for the ambient temperature of $19.5^{\circ} \mathrm{C}$. It was observed that the air temperature in the rear duct increased progressively from the duct upstream to the DAG (Fig.3a) because of heat losses through the rear wall. As a part of this cold air also infiltrated into the cabinet through PBP, it explains higher temperature of back load at the top shelf compared to the lower shelves. Similarly, higher temperature of the load at the front top shelf was observed compared to that at the lower shelves. On the same shelf, the front load temperature was relatively higher (average difference of about $1.4^{\circ} \mathrm{C}$ ) compared to the one at the back because of heat losses through the glass doors. The maximum difference $\left(2.1^{\circ} \mathrm{C}\right)$ at the top shelf can be explained by additional heat loads from the warm air infiltration through the door gaps and the heat 
conversion of visible radiation from the room and cabinet lightings. The highest and lowest load temperature positions were located at the front of the top shelf and the back of the bottom shelf, respectively.

As shown in Fig.3b, the calculated air and load temperatures agreed with the measured ones with an overall mean absolute error of about $0.2^{\circ} \mathrm{C}$. A slight over-estimated air temperature at the front can be explained by the measurement position which may not be a good representation of the entire air across the front area. Nevertheless, the load temperature is well predicted. The maximum difference of the calculated and measured load temperatures was less than $0.5^{\circ} \mathrm{C}$ for every studied position. It is worth to remind that the developed model does not take into account the air infiltration due to door openings because the airflow during door openings is too complex to be predicted by the simplified model.
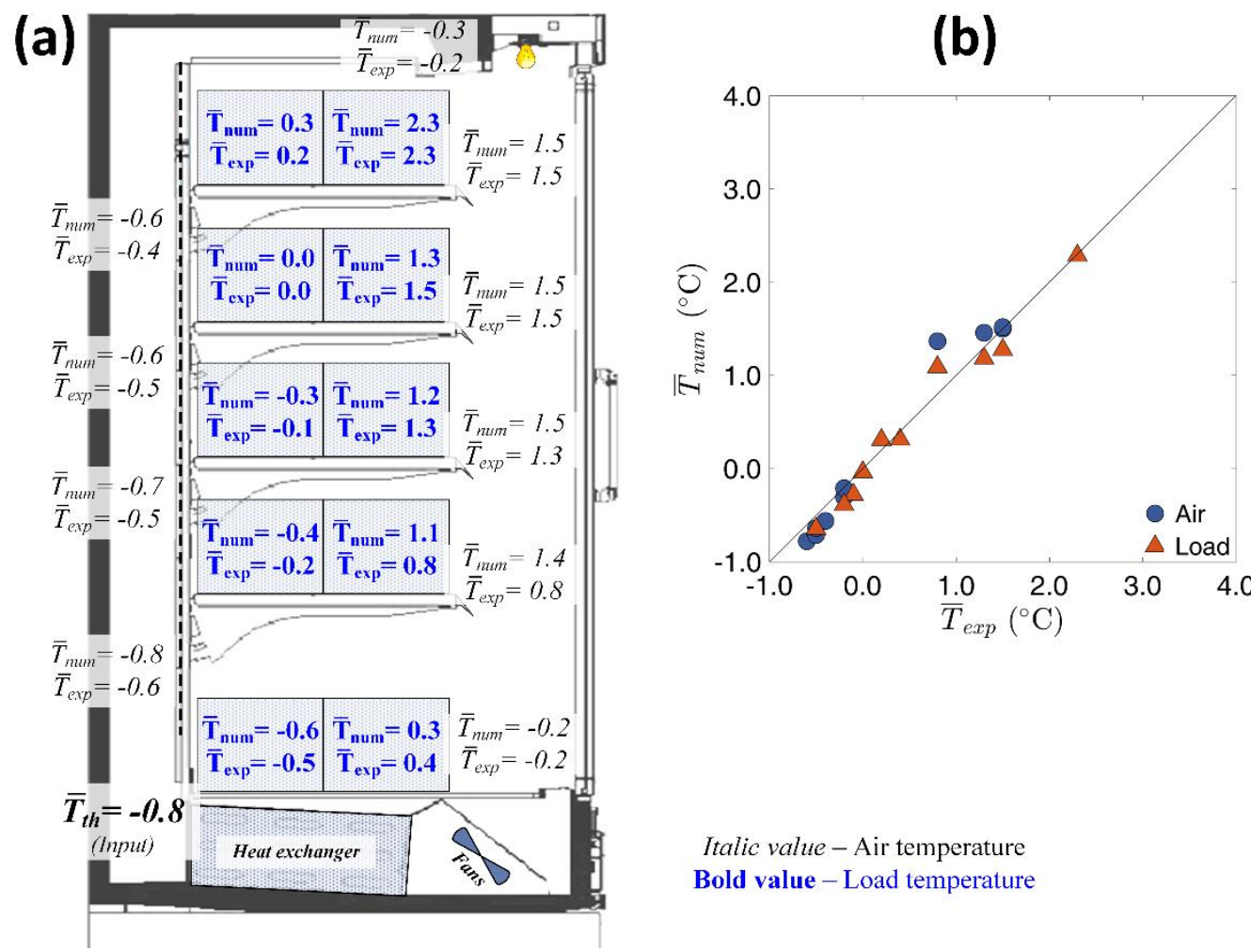

Figure 3: (a) Temperature distribution obtained from the numerical simulation $\left(\bar{T}_{\text {num }}\right)$ and measurement $\left(\bar{T}_{\text {exp }}\right)$ in a closed display cabinet for ambient temperature of $19.5^{\circ} \mathrm{C}$ (b) comparison between the predicted and measured air and load temperatures.

The validated model was further used to investigate the effect of design parameters on the load temperature in the closed display cabinet including rear wall insulation thickness $(e)$ and air infiltration rate through the door gaps $\left(\dot{m}_{g a p}\right)$. As shown in Fig.4a, doubling insulation wall thinkness resulted in a slight decrease of load temperatures (about $0.2^{\circ} \mathrm{C}$ ). Load temperatures could be notibly decreased (up to $0.7^{\circ} \mathrm{C}$ ) when the air infiltration through the door gap reduced by half (Fig.4b). These findings suggested that the temperature performance of closed refrigerated display cabinets could be improved by minimizing the door gaps of the cabinets.

\section{CONCLUSIONS}

A steady state simplified heat transfer model was developed for a closed refrigerated display cabinet. Based on a zonal approach, the display cabinet was decomposed into various heat exchange zones allowing the prediction of air and load temperatures at different positions. In the shelves-space storage, time-averaged load temperatures at 10 positions (front and back 
of the five shelves) were predicted and compared with the experimental results. It was observed that the load temperatures were well predicted by the model whereas the air temperature in the air curtain was slightly over-estimated. Possible explanation of the discrepancy between the model and the experiment is that the air temperature was measured only at one position which may not be representative of the average air temperature inside the curtain . Nevertheless, the load temperature ranges and trends in the closed display cabinet are well represented by the proposed model with a short calculation time (less than $1 \mathrm{~s}$ ). The overall mean absolute error was less than $0.2^{\circ} \mathrm{C}$, and the maximum difference of the calculated and measured load temperatures never exceeds $0.5^{\circ} \mathrm{C}$ for every studied position. Moreover, this validated model can be used to study the influence of display cabinet design on the thermal performance.
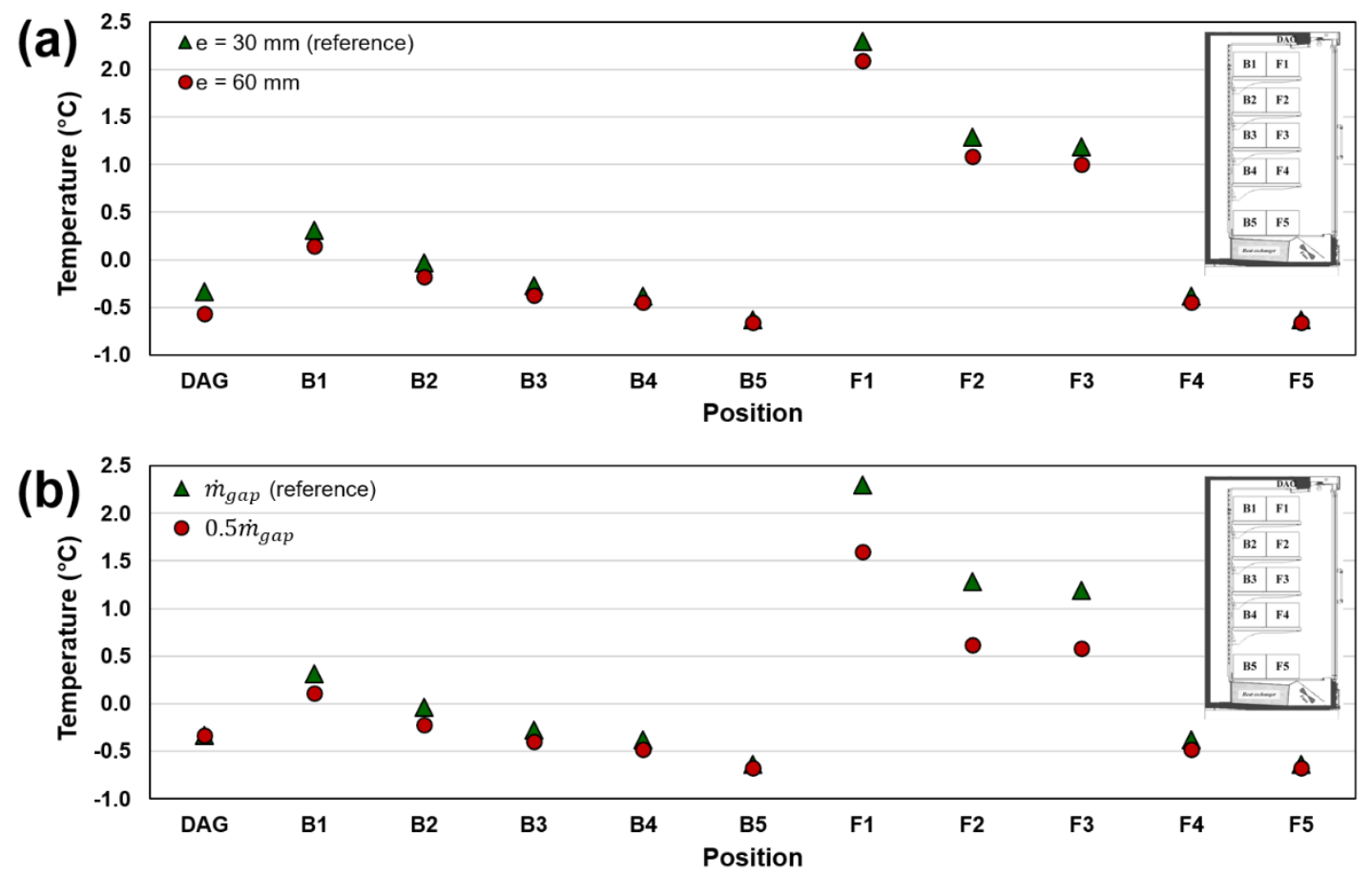

Figure 4: Numerical results showing the variation of air temperature at discharge air grille (DAG) and load temperatures with (a) wall insulation thickness and (b) air infiltration rate through the door gaps

\section{ACKNOWLEDGEMENT}

This research was granted by King Mongkut's Institute of Technology Ladkrabang, Thailand, National Research Institute of Science and Technology for Environment and Agriculture, France and the French Embassy in Thailand.

\section{NOMENCLATURE}

$\begin{array}{ll}C_{e q} & \text { Equivalent thermal conductance, } \\ & \mathrm{W} \cdot \mathrm{m}^{-2} \cdot \mathrm{K}^{-1} \\ e & \text { thinkness, } \mathrm{m} \\ h & \text { Convective heat transfer } \\ & \text { coefficient, } \mathrm{W} \cdot \mathrm{m}^{-2} \cdot \mathrm{K}^{-1} \\ \dot{m} & \text { Mass flow rate, } \mathrm{kg} \cdot \mathrm{s}^{-1} \\ q & \text { Heating power, } \mathrm{W} \\ S & \text { Exchange area, } \mathrm{m}^{2}\end{array}$
T Temperature, ${ }^{\circ} \mathrm{C}$ or $\mathrm{K}$
$U \quad$ Overall heat transfer coefficient, $\mathrm{W} \cdot \mathrm{m}^{-2} \cdot \mathrm{K}^{-1}$
$\alpha, \beta \quad$ Exponential dimensionless heat transfer coefficient
$\delta, \gamma \quad$ Air distribution coefficient
$\theta \quad$ Dimensionless time-averaged temperature




\section{REFERENCES}

Atilio de Frias, J., Luo, Y., Kou, L., Zhou, B., Wang, Q., 2015. Improving spinach quality and reducing energy costs by retrofitting retail open refrigerated cases with doors. Postharvest Biology and Technology 110, 114-120.

Chaomuang, N., Flick, D., Denis, A., Laguerre, O., 2019. Experimental analysis of heat transfer and airflow in a closed refrigerated display cabinet. Journal of Food Engineering 244, $101-114$.

Duret, S., Gwanpua, S.G., Hoang, H.-M., Guillier, L., Flick, D., Laguerre, O., Jabri, M.E.L., Thuault, D., Hezard, B., Lintz, A., Stahl, V., Geeraerd, A., (2015). Identification of the significant factors in food quality using global sensitivity analysis and the accept-andreject algorithm. Part II: Application to the cold chain of cooked ham. Journal of Food Engineering 148, 58-65.

Evans, J.A., Scarcelli, S., Swain, M.V.L., 2007. Temperature and energy performance of refrigerated retail display and commercial catering cabinets under test conditions. International Journal of Refrigeration 30, 398-408.

Faramarzi, R.T., Coburn, B.A., Sarhadian, R., 2002. Performance and energy impact of installing glass doors on an open vertical deli/dairy display case. ASHRAE Transactions $108,673$.

Fricke, B., Becker, B., 2010. Energy use of doored and open vertical refrigerated display cases, International Refrigeration and Air Conditioning Conference. Purdue University, West Lafayette, IN, USA.

Gaspar, P.D., Carrilho Gonçalves, L.C., Pitarma, R.A., 2011. Experimental analysis of the thermal entrainment factor of air curtains in vertical open display cabinets for different ambient air conditions. Applied Thermal Engineering 31, 961-969.

Laguerre, O., Hoang, M.H., Flick, D., 2012a. Heat transfer modelling in a refrigerated display cabinet: The influence of operating conditions. Journal of Food Engineering 108, 353364.

Laguerre, O., Hoang, M.H., Osswald, V., Flick, D., 2012b. Experimental study of heat transfer and air flow in a refrigerated display cabinet. Journal of Food Engineering 113, 310-321.

Lindberg, U., Axell, M., Fahlén, P., 2010. Vertical display cabinets without and with doors-a comparison of measurements in a laboratory and in a supermarket, 1st IIR International Conference on Sustainability and the Cold Chain, Cambridge, United Kingdom.

RPF, 2016. Fermeture des meubles réfrigérés: du positif pour les clients, La Revue Pratique du Froid et du Conditionnement d'Air. Imprimerie Chirat, St-Just-la-Pendue, pp. 26-28.

Smale, N.J., Moureh, J., Cortella, G., 2006. A review of numerical models of airflow in refrigerated food applications. International Journal of Refrigeration 29, 911-930. 